\title{
Correlation between CT features and liver function and p53 expression in hepatitis, cirrhosis and hepatocellular carcinoma
}

\author{
YAHUI HU, JING WU, SHA LI and XIAOXIAO ZHAO \\ Department of Nuclear Medicine, Zhengzhou Central Hospital Affiliated to \\ Zhengzhou University, Zhengzhou, Henan 450000, P.R. China
}

Received December 27, 2017; Accepted June 27, 2018

DOI: $10.3892 / \mathrm{ol} .2018 .9144$

\begin{abstract}
This study aimed to investigate the correlation between CT features and liver function and p53 expression in hepatitis, cirrhosis and hepatocellular carcinoma (HCC). Forty patients with HCC, 30 patients with cirrhosis and 30 patients with chronic hepatitis were enrolled between December, 2015 and December, 2016. At the same time, normal liver tissues collected from 30 patients with hepatic hemangioma were used as the normal control group. All the patients were scanned by CT. Average body surface area, left outer lobe and caudate lobe volume, and the proportions of left outer lobe and caudate lobe to the whole liver were calculated. Biochemical indexes of liver function were determined. The pathological tissues of all the subjects were analyzed. Compared with the control group, total liver volume of the HCC group was significantly reduced $(\mathrm{P}<0.05)$. Compared with the HCC group, the volume of the left outer lobe increased in the hepatitis group and the cirrhosis group. Compared with control group, caudate lobe volume increased significantly in the hepatitis group $(\mathrm{P}<0.05)$. Compared with the control group, the volume of the left outer lobe and the proportion of caudate lobe to the whole liver volume was significantly increased in all three groups $(\mathrm{P}<0.05)$. Liver function-related indicators in the HCC and cirrhosis groups were significantly different from those in the control group $(\mathrm{P}<0.05)$. The expression level of p53 in $\mathrm{HCC}$ was significantly higher than that in the control group $(\mathrm{P}<0.05)$. The accuracy of diagnosis by using both $\mathrm{p} 53$ and $\mathrm{CT}$ was higher than the use of p53 or CT alone. CT can accurately measure the volume of each lobe of the liver, and p53 has important clinical values in the diagnosis of liver diseases. Thus, the reasonable combination of the two can effectively improve the diagnostic accuracy.
\end{abstract}

Correspondence to: Dr Yahui Hu, Department of Nuclear Medicine, Zhengzhou Central Hospital Affiliated to Zhengzhou University, 195 Tongbai Road, Zhengzhou, Henan 450000, P.R. China E-mail: h559d3@163.com

Key words: hepatitis, cirrhosis, hepatocellular carcinoma, computed tomography, tumor suppressor gene

\section{Introduction}

At present, hepatocellular carcinoma (HCC) is the second most common cause of cancer-related death in China, and the incidence of HCC in recent several years has shown an increasing trend $(1,2)$. The mortality rate of HCC is high. Hepatitis, cirrhosis and liver cancer belong to the trilogy of liver disease, and most patients with HCC often have varying degrees of cirrhosis $(3,4)$.

The key factor for the high mortality rate of HCC is the immature early diagnosis of HCC. HCC in early stages usually shows no specific symptoms, and most patients are diagnosed at advanced stages, leading to the high mortality rate $(5,6)$. Therefore, early diagnosis and treatment remain crucial in the treatment of HCC. Previous findings showed that hepatitis, cirrhosis and $\mathrm{HCC}$ are accompanied with different changes in liver volume (7). In addition, the occurrence of HCC is directly related to the inactivation of tumor suppressor genes and abnormal cell proliferation (8). p53 is a major tumor suppressor gene associated with most malignancies, including $\operatorname{HCC}(9,10)$.

In the present study, the volume of whole liver, left lateral lobe and caudate lobe was measured by 16 -slice spiral CT and the correlations between those features and liver function were examined. Expression of p53 in liver tissue of patients with hepatitis, cirrhosis and HCC was detected. The specificity and sensitivity of diagnosis of liver cancer were improved by combining the two different indexes.

\section{Materials and methods}

Inclusion and exclusion criteria. Patients with HCC, cirrhosis and chronic hepatitis at the Zhengzhou Central Hospital Affiliated to Zhengzhou University (Henan, China) were selected between December, 2015 and December, 2016. The patients were diagnosed by pathological examinations according to the diagnostic criteria established by WHO. This study was approved by the Ethics Committee of Zhengzhou Central Hospital Affiliated to Zhengzhou University (Henan, China), and all patients signed written informed consent.

Inclusion criteria for the study were: patients received surgical treatment; patients received no radiotherapy or chemotherapy before surgery; patients with primary HCC; patients with complete clinical record. Exclusion criteria for the study were: patients without accurate pathological diagnosis; patients 
A

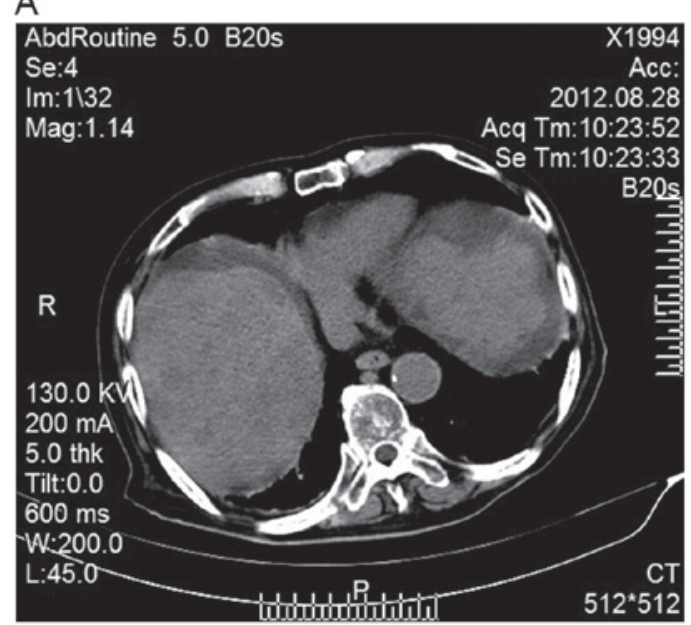

$\mathrm{B}$

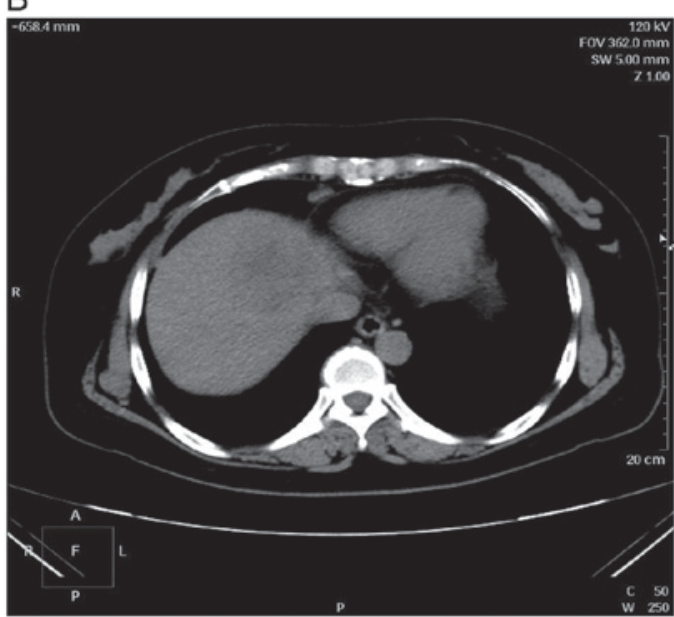

Figure 1. Conventional double-phase 16 spiral CT scanning.

treated with radiotherapy or chemotherapy before surgery; patients with metastatic liver cancer; patients with contraindications for surgery.

Clinical data. Clinical data of those patients were collected. These patients were selected using the Hospital Information System (HIS), diagnosed by Pathematology and conformed to the standard. There were 40 patients with HCC, 30 patients with cirrhosis and 30 patients with chronic hepatitis. At the same time, normal liver tissues collected from 30 patients with hepatic hemangioma were used as the normal control group. All normal liver tissues were observed under a microscope (Olympus Corporation, Tokyo, Japan), and no inflammatory cell infiltration, fibrosis and regeneration nodules and hemangioma lesions were observed.

\section{Methods}

Measurement of liver volume. Siemens Sensation 16 spiral CT scanner was used for conventional double-phase scanning. The area from the top of the diaphragm to the lower edge of liver and spleen was scanned within a breath-hold. During scanning, bolus injection of 80-100 $\mathrm{ml}$ non-ionic contrast agent elixir was performed at a speed of 2.5-3.0 ml/sec. Spiral collimation was $1.5 \mathrm{~mm}$, moving speed was $12 \mathrm{~mm} / \mathrm{sec}$, scanning layer thickness was $7.00 \mathrm{~mm}$ and reconstruction interval was $5.00 \mathrm{~mm}$. After scanning, the original data were subjected to $5 \mathrm{~mm}$ portal venous phase reconstruction, and were imported into Volume software. Edge of the liver lobes was identified from top of the septum to the lower edge of the liver and gallbladder and inferior vena cava were avoided. The volume of the liver was calculated with the threshold of 30-300 HU (Fig. 1).

Observation index. Before CT examination, the patient's height and weight were recorded to calculate body surface area. In order to avoid individual differences, volume of the whole liver, left outer lobe and caudate lobe per unit body surface was calculated.

Liver function test. Biochemical indexes of liver function were tested using TBA-120FR automatic biochemical analyzer (Toshiba, Tokyo, Japan).
Immunohistochemical detection of p53 expression. Tissues were fixed in $10 \%$ neutral formalin, followed by paraffin-embedding and slicing. Tissue sections were transferred to glass slides and baked at $70^{\circ} \mathrm{C}$ overnight. The slides were deparaffinized 3 times using xylene, and passed a graded concentrations ethanol for hydration. Citric acid buffer was used for antigen retrieval. After washing 3 times with phosphate-buffered saline (PBS), sections were incubated with $3 \% \mathrm{H}_{2} \mathrm{O}_{2}$ for $15 \mathrm{~min}$ at room temperature. The sections were incubated with primary rabbit anti-human P53 monoclonal antibody (1:700; cat. no. 2527; Cell Signaling Technology, Inc., Danvers, MA, USA) overnight at $4^{\circ} \mathrm{C}$ in a wet box. After washing 3 times with PBS, sections were incubated with secondary goat anti-rabbit monoclonal antibody (1:1,000; cat. no. 8114; Cell Signaling Technology, Inc.) for $30 \mathrm{~min}$ at room temperature. After washing 3 times with PBS, DAB color development was performed in a wet box, and color development was stopped by rinsing with tap water. The sections were soaked in hematoxylin for 1-3 min, and after washing, the sections were soaked in hydrochloric acid alcohol for 10-20 sec. The sections were rinsed, dehydrated, vitrificated and sealed with neutral resin.

Statistical analysis. SPSS 20.0 statistical software (IBM, Armonk, NY, USA) was used for the statistical analysis. Measurement data were expressed as mean \pm standard deviation (SD), and subjected to one-way ANOVA with LSD as the post hoc test. Intragroup comparisons were performed using t-test. Countable data were expressed as a percentage (\%), and comparisons were performed using a $\chi^{2}$ test. $\mathrm{P}<0.05$ was considered to indicate a statistically significant difference.

\section{Results}

Changes in liver volume and correlations with liver disease. Calculated body surface area of each group was substituted into the formula for the calculation of standard liver volume. No significant differences in calculated liver volume were found between patient groups and control group ( $\mathrm{P}>0.05)$. However, liver volume and volume index measured by $\mathrm{CT}$ in 
Table I. Changes in liver volume and correlations with liver disease.

\begin{tabular}{lccccc}
\hline Groups & Cases & Formula volume $\left(\mathrm{cm}^{3}\right)$ & CT volume $\left(\mathrm{cm}^{3}\right)$ & Volume index & Volume change rate $(\%)$ \\
\hline Hepatitis group & 30 & $1196.27 \pm 131.35$ & $1109.35 \pm 136.42$ & $0.93 \pm 0.27$ & $8.03 \pm 3.31$ \\
Cirrhosis group & 30 & $1217.54 \pm 105.46$ & $1043.92 \pm 94.57$ & $0.86 \pm 0.28$ & $14.34 \pm 4.52^{\mathrm{a}}$ \\
HCC group & 40 & $1213.08 \pm 119.48$ & $798.29 \pm 92.69^{\mathrm{a}}$ & $0.65 \pm 0.15^{\mathrm{a}}$ & $33.79 \pm 5.04^{\mathrm{a}}$ \\
Control group & 30 & $1109.99 \pm 122.26$ & $1089.65 \pm 100.69$ & $0.95 \pm 0.19$ & $8.25 \pm 2.25$ \\
t-test & - & 2.139 & 6.096 & 6.982 & 8.296 \\
P-value & - & 0.341 & 0.002 & 0.005 & 0.000 \\
\hline
\end{tabular}

${ }^{\mathrm{a} C}$ Compared with control group, $\mathrm{P}<0.05$. HCC, hepatocellular carcinoma.

Table II. Liver volume of each group.

\begin{tabular}{|c|c|c|c|c|c|c|c|}
\hline Groups & Cases & $\begin{array}{l}\text { Total liver } \\
\text { volume } \\
\left(\mathrm{cm}^{3}\right)\end{array}$ & $\begin{array}{c}\text { Total liver } \\
\text { volume/ } \\
\text { body surface } \\
\text { volume }\left(\mathrm{cm}^{3}\right)\end{array}$ & $\begin{array}{l}\text { Left outer } \\
\text { lobe } \\
\text { volume }\end{array}$ & $\begin{array}{l}\text { Left outer } \\
\text { lobe volume/ } \\
\text { body surface } \\
\text { volume }\left(\mathrm{cm}^{3}\right)\end{array}$ & $\begin{array}{c}\text { Caudate } \\
\text { lobe } \\
\text { volume }\left(\mathrm{cm}^{3}\right)\end{array}$ & $\begin{array}{l}\text { Caudate lobe } \\
\text { volume/body } \\
\text { surface } \\
\text { volume }\left(\mathrm{cm}^{3}\right)\end{array}$ \\
\hline Hepatitis group & 30 & $1109.88 \pm 336.68$ & $647.52 \pm 182.82$ & $315.39 \pm 105.78^{a}$ & $185.32 \pm 62.37^{\mathrm{a}}$ & $36.26 \pm 22.48^{a}$ & $21.65 \pm 13.11^{\mathrm{a}}$ \\
\hline Cirrhosis group & 30 & $1041.27 \pm 324.13$ & $601.24 \pm 173.29$ & $281.65 \pm 90.27^{\mathrm{a}}$ & $165.28 \pm 54.32^{\mathrm{a}}$ & $29.47 \pm 19.53$ & $16.13 \pm 10.57$ \\
\hline HCC group & 40 & $796.24 \pm 201.52^{\mathrm{a}}$ & $461.93 \pm 152.37^{a}$ & $208.59 \pm 80.10$ & $121.75 \pm 49.58$ & $21.25 \pm 14.66$ & $12.75 \pm 5.98$ \\
\hline Control group & 30 & $1225.84 \pm 216.87$ & $709.82 \pm 199.85$ & $201.52 \pm 59.17$ & $117.52 \pm 34.18$ & $27.96 \pm 15.32$ & $15.98 \pm 6.99$ \\
\hline t-test & - & 5.223 & 5.853 & 6.580 & 8.015 & 5.697 & 6.853 \\
\hline P-value & - & 0.025 & 0.009 & 0.002 & 0.000 & 0.023 & 0.011 \\
\hline
\end{tabular}

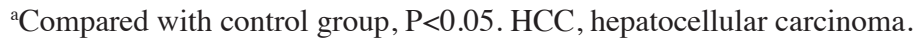

Table III. Proportions of left outer lobe and caudate lobe to the whole liver.

\begin{tabular}{lccc}
\hline Groups & Cases & $\begin{array}{c}\text { Left outer lobe/ } \\
\text { whole liver }(\%)\end{array}$ & $\begin{array}{c}\text { Caudate lobe/ } \\
\text { whole liver }(\%)\end{array}$ \\
\hline Hepatitis group & 30 & $29.72 \pm 9.29^{\mathrm{a}}$ & $3.37 \pm 1.45^{\mathrm{a}}$ \\
Cirrhosis group & 30 & $27.46 \pm 10.63^{\mathrm{a}}$ & $2.90 \pm 1.45$ \\
HCC group & 40 & $27.07 \pm 8.04^{\mathrm{a}}$ & $2.89 \pm 1.42$ \\
Control group & 30 & $16.63 \pm 4.45$ & $2.25 \pm 0.73$ \\
t-test & - & 1.236 & 1.117 \\
P-value & - & 0.159 & 0.206 \\
\hline
\end{tabular}

${ }^{\mathrm{a} C o m p a r e d}$ with control group, $\mathrm{P}<0.05$. HCC, hepatocellular carcinoma.

HCC groups were significantly lower than those in other group. Liver volume change rate in HCC group was $33.79 \pm 5.04 \%$, which was significantly higher than that in other three groups $(\mathrm{P}<0.05)$ (Table I).

Comparison of liver lobe between patient groups and control group. No significant differences in total liver volume and unit surface area were found between the hepatitis, cirrhosis and control groups $(\mathrm{P}>0.05)$, but significantly reduced values were found in the HCC group $(\mathrm{P}<0.05)$. Left outer lobe volume and unit surface area volume in the hepatitis, HCC and cirrhosis groups were significantly larger than those in the control group $(\mathrm{P}<0.05)$. Caudate lobe volume and unit surface area volume in the hepatitis group were significantly larger than those in the remaining groups, and no significant differences were found among the cirrhosis, HCC and control groups $(\mathrm{P}>0.05)$. No significant differences in the proportions of left outer lobe and caudate lobe to the whole liver were found among the groups (P>0.05) (Tables II and III).

Liver function-related indicators in each group. Liver function-related indicators in the HCC and cirrhosis groups were significantly different from those in the control group $(\mathrm{P}<0.05)$. The results showed that the liver function of hepatitis patients was normal. However, with the aggravation of liver damage, liver dysfunction became more and more obvious (Table IV).

p53 expression in each group. Positive rate of p53 expression was $45.00 \%(18 / 22)$ in the HCC group and $3.33 \%(1 / 29)$ in the cirrhosis group. The positive rate of p53 expression in cirrhosis and hepatitis was not significantly different from that in control group $(\mathrm{P}>0.05)$, but there were significant differences between HCC group and control group $(\mathrm{P}<0.05)$ (Table V).

Correlations between hepatitis, cirrhosis and HCC CT features and liver function index $A L B$. Hepatitis, cirrhosis and HCC CT features showed a high degree of consistency with 
Table IV. Liver function-related indicators in each group.

\begin{tabular}{lccccccc}
\hline Groups & Cases & ALB $(\mathrm{g} / \mathrm{l})$ & TP $(\mathrm{g} / \mathrm{l})$ & ALB/GLB & Pche $(\mathrm{V} / \mathrm{l})$ & TBIL $(\mu \mathrm{mol} / \mathrm{l})$ & TBA $(\mu \mathrm{mol} / \mathrm{l})$ \\
\hline Hepatitis group & 30 & $38.54 \pm 0.51$ & $68.57 \pm 0.77$ & $1.34 \pm 0.06$ & $5215.15 \pm 230.42$ & $2.72 \pm 0.09$ & $2.49 \pm 0.11$ \\
Cirrhosis group & 30 & $30.93 \pm 0.47^{\mathrm{a}}$ & $63.32 \pm 0.71$ & $0.93 \pm 0.05^{\mathrm{a}}$ & $2834.69 \pm 211.27^{\mathrm{a}}$ & $3.53 \pm 0.19^{\mathrm{a}}$ & $2.93 \pm 0.22^{\mathrm{a}}$ \\
HCC group & 40 & $23.59 \pm 0.41^{\mathrm{a}}$ & $57.91 \pm 0.62^{\mathrm{a}}$ & $0.65 \pm 0.02^{\mathrm{a}}$ & $2355.57 \pm 199.11^{\mathrm{a}}$ & $4.09 \pm 0.13^{\mathrm{a}}$ & $3.61 \pm 0.24^{\mathrm{a}}$ \\
Control group & 30 & $40.49 \pm 0.59$ & $71.50 \pm 0.81$ & $1.49 \pm 0.08$ & $5347.42 \pm 251.22$ & $2.91 \pm 0.11$ & $2.41 \pm 0.99$ \\
\hline
\end{tabular}

${ }^{\mathrm{a} C o m p a r e d ~ w i t h ~ c o n t r o l ~ g r o u p, ~} \mathrm{P}<0.05$. HCC, hepatocellular carcinoma.

Table V. p53 expression in each group.

\begin{tabular}{lccc}
\hline & \multicolumn{3}{c}{$\mathrm{p} 53$} \\
\cline { 2 - 4 } Groups & Cases & $\begin{array}{c}\text { Positive } \\
\mathrm{n}(\%)\end{array}$ & $\begin{array}{c}\text { Negative } \\
\mathrm{n}(\%)\end{array}$ \\
\hline Hepatitis group & 30 & $0(0.00)$ & $30(100.00)^{\mathrm{a}}$ \\
Cirrhosis group & 30 & $1(3.33)$ & $29(96.67)$ \\
HCC group & 40 & $18(45.00)$ & $22(55.00)$ \\
Control group & 30 & $0(0.00)$ & $30(100.00)$ \\
\hline
\end{tabular}

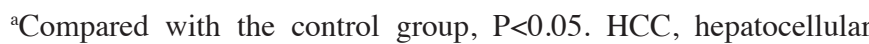
carcinoma.

Table VI. Correlations between hepatitis, cirrhosis and HCC CT features and liver function index ALB.

\begin{tabular}{lr}
\hline Groups & Correlation values \\
\hline Hepatitis group & $\mathrm{r}=0.96, \mathrm{P}<0.05$ \\
Cirrhosis group & $\mathrm{r}=0.91, \mathrm{P}<0.05$ \\
HCC group & $\mathrm{r}=0.94, \mathrm{P}<0.05$ \\
Control group & $\mathrm{r}=0.92, \mathrm{P}<0.05$ \\
\hline
\end{tabular}

HCC, hepatocellular carcinoma.

the expression level of liver function indicator ALB, and they were positively correlated (Table VI).

Correlations between hepatitis, cirrhosis and HCC CTfeatures and 553 expression. Hepatitis, cirrhosis and HCC CT features showed a high degree of consistency with the expression level of p53, and they were negatively correlated (Table VII).

Diagnostic accuracies of liver diseases by using CT. Sensitivity, specificity, positive predictive rate and negative predictive rate of CT were 50.80, 98.90, 98.30 and $62.30 \%$, respectively, while the values of p53 were 78.30, 77.80, 81.10 and $74.50 \%$, respectively. Sensitivity, specificity, positive predictive rate and negative predictive rate of CT combined with p53 was 33.60, $98.90,97.40$ and $54.92 \%$, respectively. The data suggest that the accuracy of diagnosis of liver disease by both using p53 and CT was higher than the use of p53 or CT alone (Table VIII).
Table VII. Correlations between hepatitis, cirrhosis and HCC CT features and p53 expression.

\begin{tabular}{ll}
\hline Groups & Correlation values \\
\hline Hepatitis group & $\mathrm{r}=-0.94, \mathrm{P}<0.05$ \\
Cirrhosis group & $\mathrm{r}=-0.96, \mathrm{P}<0.05$ \\
HCC group & $\mathrm{r}=-0.91, \mathrm{P}<0.05$ \\
Control group & $\mathrm{r}=-0.93, \mathrm{P}<0.05$ \\
\hline
\end{tabular}

HCC, hepatocellular carcinoma.

\section{Discussion}

In China, 110,000 patients succumb to HCC, making this disease the leading cause of death in patients with chronic liver disease, especially those with cirrhosis $(11,12)$. The inhibition of hepatitis or cirrhosis remains a major issue for the clinical treatment of HCC that needs to be resolved (13). Early diagnosis is the most effective way to improve prognosis and increase the survival rate of patients with $\mathrm{HCC}(14,15)$. HCC is directly related to cirrhosis; thus, it is crucial to detect chronic liver disease (16).

Liver volume can directly reflect the number of hepatocytes, which can be used to assess the conditions of liver diseasess. Liver volume now has been widely used in the diagnosis and treatment of acute and chronic liver diseases $(17,18)$. In this study, in the stage of hepatitis and cirrhosis, the volume of whole liver was not significantly reduced compared with that in the control group, but significantly decreased in the HCC group. In addition, the proportion of left outer lobe to whole liver was increased in each patient group compared with that in control group, and no significant differences were found among the patient groups. The data suggest that enlargement of left outer lobe can be observed in both hepatitis and cirrhosis; thus, the proportion of left outer lobe to whole liver was absolutely increased. The whole liver volume was decreased in HCC group, thus, the proportion of left outer lobe to whole liver was relatively increased. Whole liver volume was not decreased in the stages of hepatitis or cirrhosis, but left outer lobe volume was increased to maintain normal compensatory function. With the development of disease, whole liver volume was decreased and compensatory function was not needed. Thus, left outer lobe volume was not be further increased. 
Table VIII. The diagnostic accuracy of CT and p53 on HCC/\%.

\begin{tabular}{|c|c|c|c|c|c|c|}
\hline Items & Sensitivity & Specificity & $\begin{array}{c}\text { Positive } \\
\text { predictive rate }\end{array}$ & $\begin{array}{c}\text { Negative } \\
\text { predictive rate }\end{array}$ & $\mathrm{LR}^{+}$ & $\mathrm{LR}^{-}$ \\
\hline \multicolumn{7}{|l|}{ Single method } \\
\hline CT & 50.80 & 98.90 & 98.30 & 62.30 & 46.40 & 0.50 \\
\hline p53 & 78.30 & 77.80 & 81.10 & 74.50 & 3.53 & 0.28 \\
\hline \multicolumn{7}{|l|}{ Combined method } \\
\hline Positive in at least one method & 95.50 & 85.50 & 89.00 & 93.80 & 6.50 & 0.05 \\
\hline Positive in both methods & 33.60 & 98.90 & 97.40 & 54.92 & 30.25 & 0.66 \\
\hline
\end{tabular}

HCC, hepatocellular carcinoma.

p53 protein dysfunction and the development of human tumors are closely correlated with each other. The occurrence and development of HCC are directly related to the abnormal expression of p53 $(19,20)$. In this study, it was found that p53 expression level in the control group and chronic liver disease groups was relatively low, but the expression level was significantly increased in the HCC group, indicating that p53 may serve as a diagnostic marker for HCC. p53 was combined with CT to increase diagnostic accuracy. It was found that a parallel combination of p53 and HSP70 increased specificity and reduced sensitivity, while serial combination played an opposite role. Therefore, the reasonable combination of p53 and CT can be used to diagnose HCC, which is more reliable and accurate than the use of p53 or CT alone.

Therefore, the rational use of p53 and HSP70 in series or in parallel can increase both sensitivity and specificity, which is conducive to the early diagnosis of HCC.

\section{Acknowledgements}

Not applicable.

\section{Funding}

No funding was received.

\section{Availability of data and materials}

The datasets used and/or analyzed during the current study are available from the corresponding author on reasonable request.

\section{Authors' contributions}

YH recorded and analyzed the clinical data of patients. JW was involved in data acquisition. SL was responsible for indicator index. YH and XZ analyzed liver function. All authors read and approved the final manuscript.

\section{Ethics approval and consent to participate}

This study was approved by the Ethics Committee of Zhengzhou Central Hospital Affiliated to Zhengzhou University (Henan, China), and all patients signed written informed consent.

\section{Patient consent for publication}

Not applicable.

\section{Competing interests}

The authors declare that they have no competing interests.

\section{References}

1. Li H, Wang S, Wang G, Zhang Z, Wu X, Zhang T, Fu B and Chen G: Yes-associated protein expression is a predictive marker for recurrence of hepatocellular carcinoma after liver transplantation. Dig Surg 31: 468-478, 2014.

2. Ji X, Zhang Q, Du Y, Liu W, Li Z, Hou X and Cao G: Somatic mutations, viral integration and epigenetic modification in the evolution of hepatitis B virus-induced hepatocellular carcinoma. Curr Genomics 15: 469-480, 2014.

3. Bahnassy AA, Zekri ARN, El-Bastawisy A, Fawzy A, Shetta M, Hussein N, Omran D, Ahmed AAS and El-Labbody SS: Circulating tumor and cancer stem cells in hepatitis $\mathrm{C}$ virus-associated liver disease. World J Gastroenterol 20: 18240-18248, 2014.

4. Chen X, Jiang W, Yue C, Zhang W, Tong C, Dai D, Cheng B, Huang C and Lu L: Heparanase contributes to trans-endothelial migration of hepatocellular carcinoma cells. J Cancer 8: 3309-3317, 2017.

5. Gehrmann M, Cervello M, Montalto G, Cappello F, Gulino A Knape C, Specht HM and Multhoff G: Heat shock protein 70 serum levels differ significantly in patients with chronic hepatitis, liver cirrhosis, and hepatocellular carcinoma. Front Immunol 5: 307, 2014

6. Kang GH, Lee BS, Lee ES, Kim SH, Lee HY and Kang DY: Prognostic significance of p53, mTOR, c-Met, IGF-1R, and HSP70 overexpression after the resection of hepatocellular carcinoma. Gut Liver 8: 79-87, 2014.

7. Tremosini S, Forner A, Boix L, Vilana R, Bianchi L, Reig M, Rimola J, Rodríguez-Lope C, Ayuso C, Solé M, et al: Prospective validation of an immunohistochemical panel (glypican 3, heat shock protein 70 and glutamine synthetase) in liver biopsies for diagnosis of very early hepatocellular carcinoma. Gut 61: 1481-1487, 2012.

8. Liu K, Zhao X, Gu J, Wu J, Zhang $\mathrm{H}$ and Li Y: Effects of $12 \mathrm{C}^{+}$heavy ion beam irradiation on the p53 signaling pathway in HepG2 liver cancer cells. Acta Biochim Biophys Sin (Shanghai) 49: 989-998, 2017.

9. Liu K, Lee J, Kim JY, Wang L, Tian Y, Chan ST, Cho C, Machida K, Chen D and Ou JJ: Mitophagy controls the activities of tumor suppressor p53 to regulate hepatic cancer stem cells. Mol Cell 68: 281-292.e5, 2017.

10. Chai Y, Xiaoyu L and Haiyan W: Correlation between expression levels of PTEN and p53 genes and the clinical features of HBsAg-positive liver cancer. J BUON 22: 942-946, 2017.

11. EI-Emshaty HM, Saad EA, Toson EA, Abdel Malak CA and Gadelhak NA: Apoptosis and cell proliferation: Correlation with BCL-2 and p53 oncoprotein expression in human hepatocellular carcinoma. Hepatogastroenterology 61: 1393-1401, 2014. 
12. Meng X, Franklin DA, Dong J and Zhang Y: MDM2-p53 pathway in hepatocellular carcinoma. Cancer Res 74: 7161-7167, 2014.

13. Lagana SM, Salomao M, Bao F, Moreira RK, Lef kowitch JH and Remotti HE: Utility of an immunohistochemical panel consisting of glypican-3, heat-shock protein-70, and glutamine synthetase in the distinction of low-grade hepatocellular carcinoma from hepatocellular adenoma. Appl Immunohistochem Mol Morphol 21: $170-176,2013$

14. Fu Y, Xu X, Huang D, Cui D, Liu L, Liu J, He Z, Liu J, Zheng S and Luo Y: Plasma heat shock protein 90alpha as a biomarker for the diagnosis of liver cancer: An official, large-scale, and multicenter clinical trial. EBioMedicine 24: 56-63, 2017.

15. Tawada A, Kanda T and Yokosuka O: Current and future directions for treating hepatitis B virus infection. World J Hepatol 7: 1541-1552, 2015.

16. Abdelfattah MR, Abaalkhail F and Al-Manea H: Misdiagnosed or incidentally detected hepatocellular carcinoma in explanted livers: Lessons learned. Ann Transplant 20: 366-372, 2015.
17. Lun-Gen L: Antiviral therapy of liver cirrhosis related to hepatitis B virus infection. J Clin Transl Hepatol 2: 197-201, 2014.

18. Zhang D and Xu A: Application of dual-source CT perfusion imaging and MRI for the diagnosis of primary liver cancer. Oncol Lett 14: 5753-5758, 2017.

19. Moreira AJ, Rodrigues G, Bona S, Cerski CT, Marroni CA, Mauriz JL, González-Gallego J and Marroni NP: Oxidative stress and cell damage in a model of precancerous lesions and advanced hepatocellular carcinoma in rats. Toxicol Rep 2: 333-340, 2014.

20. Wu W, Liu S, Liang Y, Zhou Z, Bian W and Liu X: Stress hormone cortisol enhances Bcl-2 like-12 expression to inhibit p53 in hepatocellular carcinoma cells. Dig Dis Sci 62: 3495-3500, 2017. International (CC BY-NC-ND 4.0) License. 